\title{
Solid Index Variation of Different Types of Bioreactors to Handle Rural Garbage
}

\author{
Hong $\mathrm{Li}^{1}$, Min Zheng ${ }^{1,2}$ and Dan Liu ${ }^{1,{ }^{*}}$ \\ ${ }^{1}$ Faculty of Geosciences and Environmental Engineering, Southwest Jiaotong University, Chengdu, \\ China \\ ${ }^{2}$ China Railway Eryuan Engineering Group Co. Ltd, Chengdu, China
}

\begin{abstract}
Keywords: Anaerobic - semi - aerobic; bioreactor; rural garbage; leachate
Abstract. According to the characteristics of anaerobic, aerobic and semi-aerobic bioreactor landfill, combined with the status of rural garbage disposal. Indoor simulation comparison tests were carried out between anaerobic (R3-I) - semi-aerobic (R3-II) united bioreactor and anaerobic (R1), semi-aerobic (R2) bioreactor to handle Rural garbage solid indicators. The results shows that the cumulative settlement number of anaerobic unit (R1, R3-I) has logarithm relation versus time, while the cumulative settlement number of semi-aerobic unit (R2, R3-II) is linear versus time. The BDM of garbage in semi-aerobic unit (R2, R3-II) declined faster than that of anaerobic unit (R1, R3- I). The landfill of anaerobic - semi-aerobic united bioreactor can facilitate the degradation of nitrogen substances, and is advantageous than that anaerobic bioreactor landfill and semi-aerobic bioreactor landfill runs separately. During each test, garbage column aqueous rates maintained at a high level and changed slightly.
\end{abstract}

\section{Introduction}

China's rural garbage are generated about 300 million tons, accounting for about $75 \%$ of municipal solid waste generation, and grows at a rate of $8 \%$ to $10 \%$ annually. Rural garbage problem is not only related to the living environment and health of farmers, but also related to the construction of a new socialist countryside, so it is needed to solve our environmental problems.

Currently, bioreactor research focuses on directions of anaerobic bioreactor, aerobic bioreactor, semi-aerobic and anaerobic-aerobic united bioreactor. Anaerobic bioreactor landfill has advantages of accelerating landfill stable, recycling methane gas, etc., but the long-term leachate ammonia concentration is high and the post-COD concentration decay slowly. Human garbage layer aeration of aerobic bioreactor landfill can accelerate landfill stabilization. Semi-aerobic bioreactor landfill will not only accelerate the stabilization of the landfill, but also can effectively resolve the accumulation of organic acids and ineffective treatment of anaerobic and ammonia and other issues bioreactor landfill exists, but it is not conducive to methane recovery and utilization.

In the background of building a new rural area, suitable bioreactor for processing rural garbage landfill become need of the times. The two landfill cells group constructed are anaerobic - semi aerobic bioreactor of fresh garbage, and this type of bioreactor combines anaerobic bioreactor and semi-aerobic bioreactor advantages, without going through the oxygen supply power equipment, suitable for promotion in rural areas.

In this study, anaerobic, semi-aerobic and anaerobic-semi-aerobic bioreactors were adopted to handle rural waste. The terms of solid phase indicators variation and waste settlement of each device are discussed, which provides a theoretical basis for the rapid and stable development of technology to handle rural waste using anaerobic - semi - aerobic bioreactor.

\section{Experimental set-up and method}

\section{Experimental set-up}

Anaerobic simulator (R1), semi-aerobic simulator (R2) and anaerobic - semi - aerobic simulator (anaerobic unit is R3-I, semi-aerobic unit is R3-II) are made of $1.1 \mathrm{~m}$ high, PVC tube with inner diameter of $300 \mathrm{~mm}$ as a garbage reaction column, leachate collection tube $(\Phi 25 \mathrm{~mm})$ is disposed at 
the bottom of the cylinder. Semi-aerobic unit has airway $(\Phi 25 \mathrm{~mm})$ with opening ratio of $12.5 \%$. Anaerobic - semi - aerobic simulation set-up is shown in Fig.1.

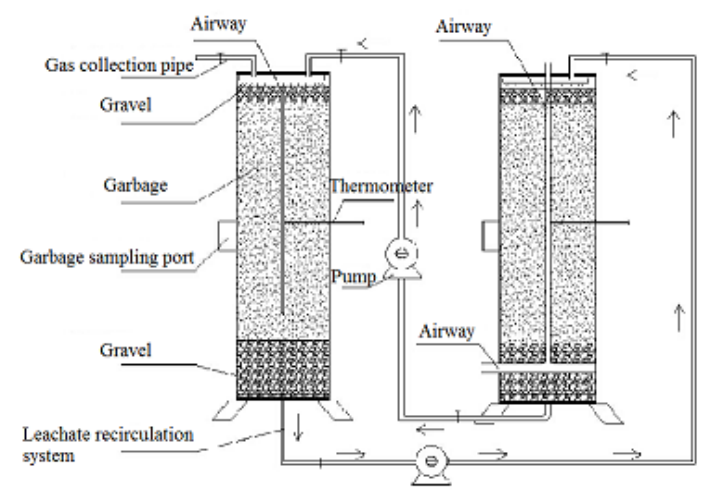

Fig.1 Schematic diagram of experimental set-up

\section{Sample components of test garbage}

The composition, generation and changes of garbage in rural area is closely related to rural economy and living habits. With the improvement of living standards in rural areas, the kitchen garbage proportion in rural garbage increases year by year. Rural garbage used in this experiment are taken from a new rural city of Dujiangyan. The mass percentage of garbage components share: kitchen waste(52.17\%), paper(14.07\%), rubber(15.32\%), textile(10.77\%), wood and bamboo(2.40\%), ceramic(1.76\%), glass(2.06\%), metal(0.5\%), mixed class(0.75\%), other classes(0.2\%). Garbage include moisture content of 66.95\%, combustible concentration of 81.61\%, ash of $15.95 \%$, biodegradation degree of $65.93 \%$, and total nitrogen of $14.03 \mathrm{~g} / \mathrm{kg}$. The sampling results show that the organic matter content in garbage component in new rural area is higher than traditional rural garbage, mainly due to the rural residents' new type of gathering lifestyle and living standards.

Garbage filling height, the volume and density of each column are shown in Table 1.

Table 1. Filling parameters of garbage columns

\begin{tabular}{cccc}
\hline Model number & Filling height $(\mathrm{cm})$ & Filling volume $(\mathrm{kg})$ & Filling density $\left(\mathrm{kg} / \mathrm{m}^{3}\right)$ \\
\hline R1、R3-I & 80 & 40.0 & 707.714 \\
R2、R3-II & 90 & 42.0 & 660.585 \\
\hline
\end{tabular}

Test organization implementation and monitoring method

According to Chengdu rainfall, simulate the rainfall monthly, and leachate recirculation frequency is one time per $3 \mathrm{~d}$, and recharge amount is fully recharge.

Water content was determined by drying method, and combustible concentration and ash were determined by burning method. The biodegradability (BDM) was determined by potassium dichromate method, and total nitrogen was measured by semi-micro Kjeldahl method. Garbage settlement value was determined indirectly using a glass rod.

\section{Results and discussion}

\section{Settling properties}

As can be seen from Fig.2, the cumulative settlement number of R1 and R3-I has a logarithm relation versus time. R-squared values were 0.9879 and 0.9865 . The cumulative settlement number of semi-aerobic unit (R2, R3-II) has a linear relation versus time. R-squared value were 0.9873 and 0.9895, respectively. Landfill garbage had rapid subsidence at the beginning, which was mainly the result of physical degradation and aerobic peristaltic degradation early. After 40d, R1 and R3-I had insufficient supply of oxygen, and aerobic microbial activity was inhibited, and anaerobic bacteria gradually became dominant in the system, resulting in slowing the rate ofgarbage decomposition. R2 and R3-II were equipped with airways, and air can replenish the oxygen consumed in the column. In 
the semi-aerobic garbage column, different areas had both aerobic bacteria and anaerobic bacteria, and abundant bacteria accelerated the degradation of garbage in anaerobic garbage column, organic eluted from R3-I was degraded in R3-II. Thus, the cumulative settlement amount in R3-I was always greater than that in R1 column, while the cumulative settlement amount in R3-II is less than R2.

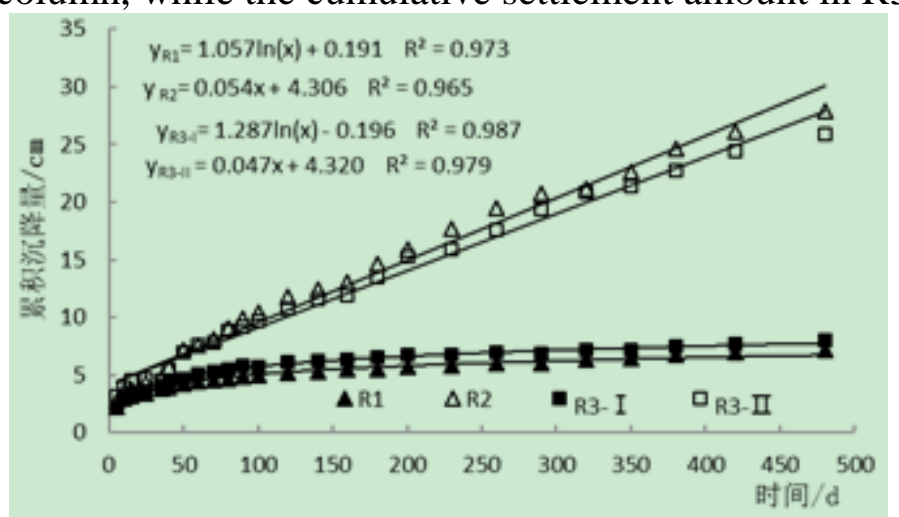

\section{BDM}

Fig.2 Settlement of refuse surface measured during column test

As can be seen from Fig.3, BDM value trend in each garbage column is highly consistent over time, showing a downward trend. Overall, BDM of garbage within the semi-aerobic unit declined faster than that within anaerobic unit. Before the first 250d, BDM within four garbage columns changed not obviously, and after that, BDM degradation rate in the semi-aerobic unit was significantly faster than that in anaerobic unit. Compared with the anaerobic set-up, semi-aerobic and anaerobic-semi-aerobic devices can better promote the garbage degradation.

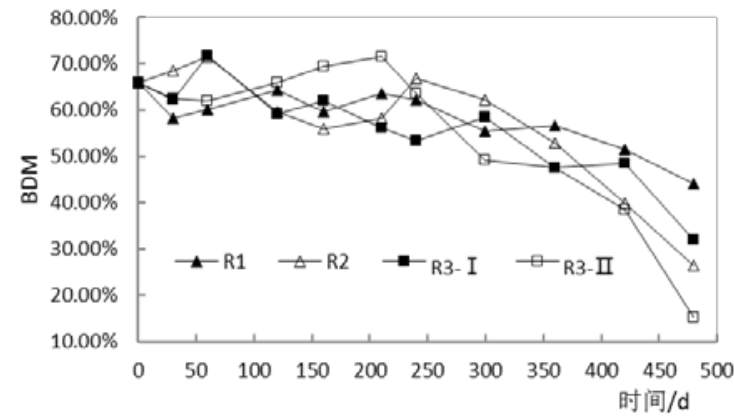

\section{Combustible concentration}

Fig.3 Change trends of BDM measured during column test

Fig. 4 shows that the initial combustible content of test garbage in experiment was $81.6 \%$, and the combustible content of garbage in the garbage column was between $68.1 \%-74.8 \%$ at the end of experiment. Combustible content of garbage in each column decreased larger at about 200d, and this trend is similar to the BDM change. As the plastic material and other refractory had a large proportion, the combustible concentration content in each column garbage had less reduction at the end of the experiment.

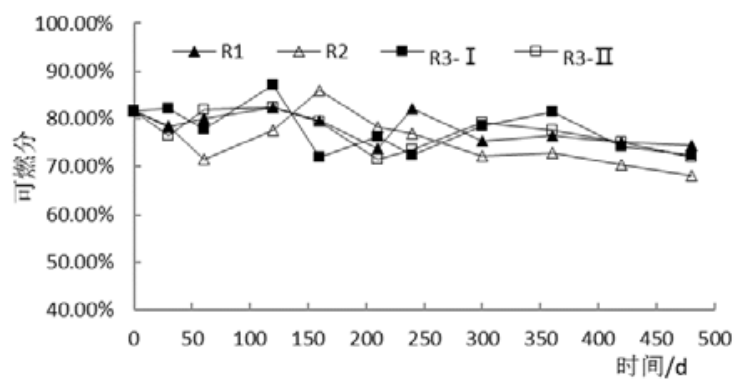

Fig.4 Change trends of combustible concentration measured during column test 


\section{Total nitrogen}

As can be seen from Fig.5, when the experiment ran to the end, The total nitrogen content in solid phase garbage of each column had a slight decline compared to the trend of landfill garbage, but there were also intermediate wave phenomena, mainly due to the solid phase sample inhomogeneity. The total nitrogen in anaerobic-semi-aerobic model garbage column (R3-I and R3-II) decreased more obviously than that of R1 and R2 garbage column. Thus, the landfill of anaerobic - semi-aerobic united bioreactor can facilitate the degradation of nitrogen substances, and is advantageous than that anaerobic bioreactor landfill and semi-aerobic bioreactor landfill runs separately.

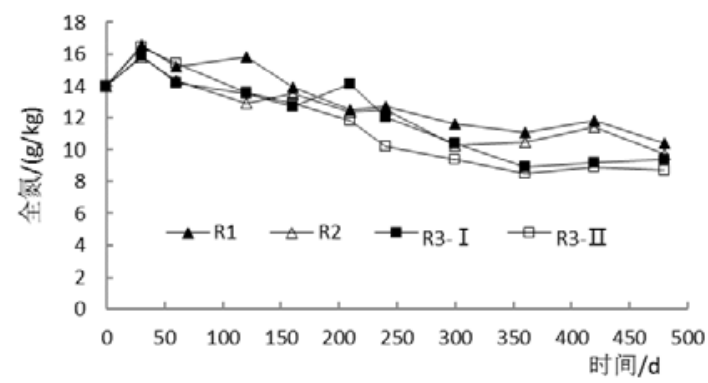

Fig.5 Change trends of total nitrogen measured during column test

\section{Moisture content}

As can be seen from Fig.6, the initial moisture content of experimental loading garbage was 66.95\%. During the whole experiment, the moisture content of garbage maintained at $65 \%$ to $75 \%$ range. Because of the recharge operations and regular rainfall simulation operation, the moisture content in garbage column during each test maintained at a high level, and changed slightly. The moisture difference between semi-aerobic and anaerobic column changed also not significant.

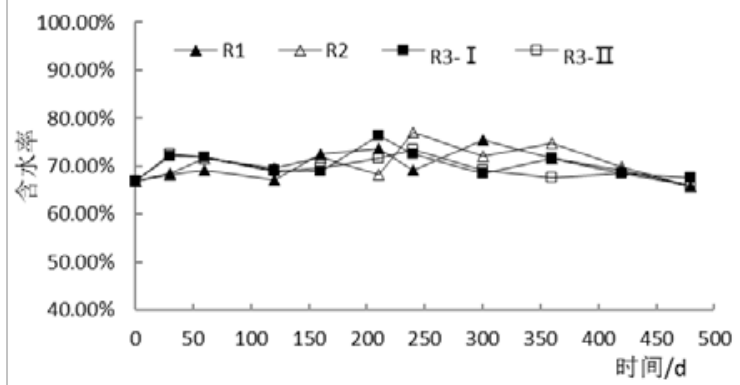

Fig. 6 Change trends of moisture content measured during column test

\section{Conclusions}

1) The garbage settlement of inner anaerobic-semi-aerobic bioreactor is between anaerobic bioreactor and semi-aerobic bioreactor, wherein the cumulative settlement number of anaerobic unit (R1, R3-I) has a good logarithm relation versus time, while the cumulative settlement number of semi-aerobic unit (R2, R3-II) has a good linear relation versus time.

2) BDM value trend in each garbage column is highly consistent over time, showing a downward trend. Overall, BDM of garbage within the semi-aerobic unit declined faster than that within anaerobic unit. After the first 250d, BDM degradation rate in the semi-aerobic unit was significantly faster than that in anaerobic unit.

3) The initial combustible concentration content of test garbage in experiment was $81.6 \%$, and the combustible concentration content of garbage in the garbage column was between $68.1 \%-74.8 \%$ at the end of experiment. Combustible concentration content of garbage in each column decreased larger at about 200d, and this trend is similar to the BDM change.

4) The total nitrogen content in solid phase garbage of each column had a slight decline compared to the trend of landfill garbage, but there were also intermediate wave phenomena, mainly due to the solid phase sample inhomogeneity. The total nitrogen in anaerobic-semi-aerobic model garbage column (R3-I and R3-II) decreased more obviously than that of R1 and R2 garbage column. 
5) The moisture content maintained at $65 \%$ to $75 \%$ range. Because of the recharge operations and regular rainfall simulation operation, the moisture content in garbage column during each test maintained at a high level, and changed slightly. The moisture difference between semi-aerobic and anaerobic column changed also not significant.

\section{References}

[1] Guan D, Qiu C. Problems situation and countermeasures of Rural garbage. China Resources Comprehensive Utilization, 2008, 26(3): 29-31.

[2] Ding Ym, He G, Rong S, et al. Treatment and disposal countermeasures of garbage in rural areas. Guangdong Agricultural Sciences, 2011, 17(2): 136-143.

[3] Liu C, et al. Robust $H_{\infty}$ control for satellite attitude control system with uncertainties and additive perturbation. International Journal of Science, 2014, 1(2): 1-9.

[4] Nguyeu N.S.. Microorganisms in landfill bioreactors for accelerated stabilization of solid wastes. Journal of bioscience and bioengineering. 2012, 114(03): 243-250.

[5] Mostafa W, Bioreactor landfills: experimental and field results. Waste Management, 2002, 22: 7-17.

[6] Delia T. S, Osman N. A. Impact of leachate recirculation and recirculation volume on stabilization of municipal solidwastes in simulated anaerobic bioreactors. Process Biochemistry, 2004, 39: 2157-2165.

[7] Sang N. N., Soda S, Sei K, et al. Effect of aeration on stabilization of organic solid waste and microbial population dynamics in lab-scale landfill bioreactors. Journal of Bioscience and Bioengineering, 2008, 5: 425-432.

[8] Jun D., Yong S. Z., Mei H., et al. Influence of alkalinity on the stabilization of municipal solid waste in anaerobic simulated bioreactor. Journal of hazardous materials, 2009, 163(2): 717-722

[9] Li G. Study on the degradation of solid-phase based on the united bioreactor landfill and the optimal conditions on semi-aerobic aged refuse biofilter.Chengdu: Southwest Jiaotong University, 2011.

[10] Zha S, Liu D, Li Q. Experimental research on the semi - aerobic landfill unit in Tibetan Plateau. Chinese Journal of Environmental Engineering, 2007, 1(8): 120-125.

[11] Liu C. Mass and mass center identification of target satellite after rendezvous and docking. Proceedings of 11th World Congress on Intelligent Control and Automation, 2014: 5802-5807. 